\title{
Modeling Collective Decision-Making Processes with the KAPSARC Toolkit for Behavioral Analysis
}

\author{
J. Andrew Howe \\ King Abdullah Petroleum Studies and \\ Research Center, Riyadh, Saudi Arabia \\ Riyadh, Saudi Arabia \\ john.howe@kapsarc.org
}

\author{
Ben Wise \\ King Abdullah Petroleum Studies and \\ Research Center, Riyadh, Saudi Arabia \\ Riyadh, Saudi Arabia \\ ben.wise@kapsarc.org
}

\author{
Brian Efird \\ King Abdullah Petroleum Studies and \\ Research Center, Riyadh, Saudi Arabia \\ Riyadh, Saudi Arabia \\ brian.efird@kapsarc.org
}

\begin{abstract}
In this article, we briefly introduce the reader to the KAPSARC Toolkit for Behavioral Analysis (KTAB). KTAB is a toolkit for building models of collective decision-making processes (CDMP), and simulating them. KTAB is being developed by the King Abdullah Petroleum Studies and Research Center to meet the need for widely available, state-of-the-art, supported, transparent, and open-source software that facilitates the modeling and analysis of CDMPs. We summarize insights from two case studies modeled with KTAB, in which important policy questions in the Arab Gulf region were modeled using two different forms of CDMP models.

We document the two forms of quantitative CDMP models used, both based on the informal exertion of influence. This is an important set of models, because actual votes cast in many situations are ultimately the result of prior informal negotiation. The Spatial Model of Politics is a powerful tool for the political analyst modeling policy questions which can be represented as a multidimensional continuous spectrum. However, not all policy questions can be represented in this manner. The Probabilistic Condorcet Election is a second, and completely general, form of CDMP model that imposes almost no structure on the problem analyzed.
\end{abstract}

\section{CCS CONCEPTS}

- Applied computing $\rightarrow$ Sociology; Decision analysis; • Computing methodologies $\rightarrow$ Modeling and simulation;

\section{KEYWORDS}

Condorcet Election, Collective Decision-Making Process, Social Simulation, Spatial Model of Politics, Bargaining, Negotiation

\section{ACM Reference format:}

J. Andrew Howe, Ben Wise, and Brian Efird. 2017. Modeling Collective Decision-Making Processes with the KAPSARC Toolkit for Behavioral Analysis. In Proceedings of CSS '17, Santa Fe, NM, USA, October 19-22, 2017, 13 pages.

https://doi.org/10.1145/3145574.3145589

Permission to make digital or hard copies of all or part of this work for personal or classroom use is granted without fee provided that copies are not made or distributed for profit or commercial advantage and that copies bear this notice and the full citation on the first page. Copyrights for components of this work owned by others than ACM must be honored. Abstracting with credit is permitted. To copy otherwise, or republish to post on servers or to redistribute to lists, requires prior specific permission and/or a fee. Request permissions from permissions@acm.org.

CSS '17, October 19-22, 2017, Santa Fe, NM, USA

(C) 2017 Association for Computing Machinery.

ACM ISBN 978-1-4503-5269-7/17/10 ..\$15.00

https://doi.org/10.1145/3145574.3145589

\section{INTRODUCTION}

- United States citizens head to the polls to cast votes for their political representatives on the second Tuesday of November every 4 years.

- Shareholders of Alphabet (Google's parent) voted for / against the board of directors in June 2017; holders of class A stock cast one vote per share, while holders of class B cast ten votes per share.

- Supporters donate money to fund political candidacy campaigns; candidates spend said funds to persuade citizens to vote for them

- "Big Oil" organizations lobby United States senators to legislate in their favor, as do environmentalists.

- A school board debates and jointly determines a budget that asymmetrically allocates funds to different departments.

What do these situations all have in common? They can all be seen as what we might call a collective decision-making process (CDMP). Other terms which we might use - "negotiation" or "bargaining" - are rather imprecise and often carry undesirable connotative baggage. Observe that our conception of a CDMP encompasses formal voting and the informal exertion of influence. Indeed, the informal exertion of influence is arguably more fundamental than formal voting, as votes cast during formal voting are often a result of prior informal negotiation.

Quantitative modeling of CDMPs is an important aspect of both game theory and analytical politics. The ability to form, test, and validate a hypothesis about how actors in a CDMP will behave can be invaluable. Modeling of CDMPs has a long history - at least as far back as $18^{\text {th }}$ century France. The revolutionary Marquis de Condorcet [16] observed that when there are more than 2 candidates, majority voting can often lead to paradoxical results because collective preferences aren't always transitive (candidate A is preferred to candidate $\mathrm{B}$, who is preferred to candidate $\mathrm{C}$, but candidate $\mathrm{C}$ is preferred to candidate A). Jumping forward two centuries, the ideas of Condorcet and other early voting theorists had remained in relative obscurity until Duncan Black introduced his Spatial Model of Politics and Median Voter Theorem as a way to get around this problem of cycling [6]. Shortly thereafter, Kenneth Arrow further qualified cycling with his eponymous impossibility theorem [3, 4]. More recently, several authors have introduced randomness into quantitative models of CDMPs to ensure the existence of equilibria (see $[17,26,37]$ ).

Since [6], several researchers have developed various forms of spatial CDMP models. Some of the most prominent examples include: the Expected Utility Model $[10,11]$, the Senturion model 
[1], and the Log-rolling (or Exchange) Model [32, 33]. Bruce Buena de Mesquita, in particular, has extensively published various revisions and applications of his models [8, 9, 12-14]. However, the algorithms have been frequently described in an imprecise and obfuscated manner, model source code has remained closed, and other researchers have had difficulty reproducing their results $[5,31]$. The desire to bring these types of models to a wider research community, in an open-source and reproducible medium, led to the creation of the KAPSARC Toolkit for Behavioral Analysis (KTAB).

In this paper we will focus on CDMPs based on the informal exertion of influence. We will begin in Section 2 by discussing models of voting. The concept of voting models is easily generalized to situations where neither formal voting, nor any kind of voting as such, actually takes place. Rather, the models generalize to the concept of the exertion of influence, which is fundamental to the concept of a CDMP. From there, we will discuss how generalized voting and the formation of advocacy coalitions determine the winner of a Condorcet Election. Sections 3 and 4 discuss the Spatial Model of Politics and Probabilistic Condorcet Election. What follows is a brief exposition which skips many details. For more details, we direct the interested reader to the resources in the bibliography; [39] is an especially thorough overview.

These, and other CDMP models, have been encoded in KTAB, an open-source toolkit and framework for developing and simulating both spatial and non-spatial CDMPs; it is briefly discussed in Section 5. Section 6 documents results and unique insights generated by KTAB models from two cases studies of real situations. The first case study regards public policy to facilitate a transition away from carbon-intense energy in the UAE, as part of their Energy Strategy 2050. The political feasibility of six different policy instruments was analyzed; one instrument was found to be politically infeasible, two had weakly supportive consensus, and the remaining three are at least moderately feasible. In the second case study, a nonspatial model of politics is used to identify an agricultural crop mix in Saudi Arabia that optimally balances the need to reduce water consumption, maintain food source stability, and respect cultural sensitivities. This is important because the Ministry of Agriculture has set a target of $30 \%$ water use reduction by 2030 , and nearly $90 \%$ of of water is used for agriculture. The most politically feasible crop mix actually surpasses this target. We finish with concluding remarks in Section 7.

\section{MODELING COLLECTIVE DECISION-MAKING PROCESSES}

In a basic model of negotiation, there are $A$ actors, each of which advocates some option $\theta_{i}(i=1,2, \ldots, A)$, such that $\theta_{i} \in \Omega ; \Omega$ is the exclusive and exhaustive set of possible options. The set of options advocated by all actors is called the state $S$, where $S \in \Omega^{A}$. In this article, we focus on dynamic collective decision-making processes in which actors can iteratively change their states as a result of influence from other actors. Hence, we can also use $S_{t}$ to indicate the state of the $t^{\text {th }}$ iteration of the CDMP. The details of this dynamics process may vary depending on the type of CDMP model employed, but the general algorithm followed is:

(i) determine initial state, including all actors, their initiallyadvocated options, and other required data (ii) compute a measure of group consensus, to be used to determine when the CDMP has converged and consensus is reached

(iii) allow actors to attempt to influence others to shift their advocacy

(iv) recompute the measure of group consensus; we say the CDMP has converged and finish if it has not changed enough, otherwise, go back to (iii)

Exertion of influence is the foundation of collective decisionmaking processes - actors exert influence in an attempt to persuade others to join them in their advocacy. This exertion of influence can occur in many different ways, examples include: voting at the polls for political representatives (single vote), voting in corporate shareholder meetings (votes proportional to shares held), informal persuasion as in lobbyists influencing US senators, or the negotiation between a trade union and corporation. All of these situations are instances of generalized voting. Throughout this article, we may refer to all of these as "voting"; whether it's a formal vote or informal exertion of influence will depend on the voting model used.

\subsection{Generalized Voting - Exertion of Influence}

In a choice between any pair of options $\theta_{j}, \theta_{k} \in \Omega$, actors can exert influence, or vote, to try to get the group to adopt one or the other (in this quantitative formalism, there is generally no idea of "voting for $\theta_{j}$ " alone: there is only pairwise "voting for $\theta_{j}$ over $\theta_{k}$ "). The influence exerted by the $i^{\text {th }}$ actor is written as $v_{i}\left(\theta_{j}: \theta_{k}\right)$, where positive values favor $\theta_{j}$ and negative values favor $\theta_{k}$. The simplest formal voting system is "one person, one vote": each actor exerts influence by casting a single indivisible vote for $\theta_{j}(v=+1)$, for $\theta_{k}$ $(v=-1)$, or for some other option $(v=0)$. This can be seen as a special case of the exertion of informal influence, in which votes could be measured as real values.

There are many ways to compute these real-valued generalized votes. The simplest is binary voting, in which an actor exerts all its influence to support a preferred option, no matter how small the perceived difference in utilities. This voting rule is shown here, where the influence of the $i^{\text {th }}$ actor is $w_{i}$, and the utility derived from option $\theta_{j}$ is $u_{i}\left(\theta_{j}\right)$.

$$
v_{i}\left(\theta_{j}: \theta_{k}\right)= \begin{cases}+w_{i} & u_{i}\left(\theta_{j}\right)>u_{i}\left(\theta_{k}\right) \\ -w_{i} & u_{i}\left(\theta_{j}\right)<u_{i}\left(\theta_{k}\right)\end{cases}
$$

As with several CDMP models, we define the $i^{\text {th }}$ actor's influence $w_{i}$ as the product of capability $C_{i}$, and salience $S_{i}$. The meaning of capability should be obvious; salience refers to how much the actor cares about the issue at hand. Salience is an important consideration. For example, in a two dimensional CDMP model, the $i^{\text {th }}$ actor may have high salience for the first issue, but low salience for the second. If the $j^{\text {th }}$ actor's saliences are reversed, they can each compromise on the issue of less concern and form a coalition (as in the Logrolling model of Stokman [32,33]).

There are several plausible alternatives to binary voting. Of these, the proportional voting rule is both intuitively plausible, and has desirable mathematical properties. Proportional voting quantifies an actor's exertion of influence in proportion to its perception of the difference in utilities. The proportional voting rule, which is 
used in the case studies presented, is:

$$
v_{i}\left(\theta_{j}: \theta_{k}\right)=w_{i}\left[u_{i}\left(\theta_{j}\right)-u_{i}\left(\theta_{k}\right)\right]
$$

It is common to normalize utilities to the $[0,1]$ von Neumann range, so that the difference in utility between two options is always bounded by \pm 1 , which keeps an actor's vote in the $\left[-w_{i},+w_{i}\right]$ range. For example, if an actor can exert influence by casting 1.618 votes, $w_{i}=1.618$, and his vote can range from +1.618 votes (for $\theta_{j}$ ) to -1.618 votes (for $\theta_{k}$ ).

Proportional voting is designed to model a wide choice of means of exerting influence, an implicit budget on exerting influence, an intrinsic cost to exerting influence, or all three. Typical examples include spending money to fund political relations campaigns, nations deploying military force to pressure other nations, special interest groups lobbying for tax and subsidy policies, and so on. Political parties and special interest groups expend their campaign funds carefully, expending little or no resources on minor issues and making the largest expenditures on the most important issues, so proportional voting is a reasonable model of their behavior.

No matter which voting rule is used, the total group preference for option $\theta_{j}$ over $\theta_{k}$ is simply the sum of the votes

$$
V\left(\theta_{j}: \theta_{k}\right)=\sum_{i=1}^{A} v_{i}\left(\theta_{j}: \theta_{k}\right),
$$

which can be split into the total support for each option. The coalition supporting $\theta_{j}$ over $\theta_{k}$ is the set of actors exerting positive net influence,

and its strength is

$$
c\left(\theta_{j}: \theta_{k}\right)=\left\{i \mid v_{i}\left(\theta_{j}: \theta_{k}\right)>0\right\},
$$

$$
s\left(\theta_{j}: \theta_{k}\right)=\sum_{i \in c\left(\theta_{j}: \theta_{k}\right)} v_{i}\left(\theta_{j}: \theta_{k}\right) .
$$

For the opposite perspective of coalitions supporting $\theta_{k}$ over $\theta_{j}$, symmetric definitions of $c\left(\theta_{k}: \theta_{j}\right)$ and $s\left(\theta_{k}: \theta_{j}\right)$ obviously apply. Clearly, the strength for an option in a pair is simply the sum of the influence exerted by the coalition supporting that option, so the total group preference (3) is the excess of influence favoring $\theta_{j}$ over those favoring $\theta_{k}$ :

$$
V\left(\theta_{j}: \theta_{k}\right)=s\left(\theta_{j}: \theta_{k}\right)-s\left(\theta_{k}: \theta_{j}\right)
$$

In the dynamic CDMPs discussed in this paper, actors' influences $\left(C_{i}, S_{i}, w_{i}\right)$ and utility functions $u_{i}$ are constant. Only their advocated positions $\theta_{i}$ evolve.

\subsection{Condorcet Election}

The situation where $V\left(\theta_{j}: \theta_{k}\right)>0$ - we say that $\theta_{j}$ dominates $\theta_{k}$ can also be written as $\theta_{j}>\theta_{k}$ to emphasize the static fact that $\theta_{j}$ is chosen over $\theta_{k}$, or as $\theta_{k} \longrightarrow \theta_{j}$ when we wish to emphasize that $\theta_{j}$ could follow $\theta_{k}$ in a dynamic, stepwise CDMP. An expression like $a \longrightarrow b \longrightarrow c \longrightarrow d$ is a four-element dominance sequence, where each option is dominated by the following option. Since at least the Marquis de Condorcet [16], dominance sequences such as this have been known to cycle indefinitely (i.e., $a \longrightarrow b \longrightarrow c \longrightarrow d \longrightarrow a$ ) and have no winning option unless special conditions are imposed. However, if there is one option $\theta_{j}$ which dominates over all pairwise comparisons,

$$
\forall \theta_{k}, \theta_{j}: V\left(\theta_{j}: \theta_{k}\right)>0
$$

we call it the Condorcet Winner. The entire process of determining $v_{i}\left(\theta_{j}: \theta_{k}\right), s\left(\theta_{j}: \theta_{k}\right)$, and $V\left(\theta_{j}: \theta_{k}\right)$ for a particular state is sometimes termed a Condorcet Election over that set of options [16].

Note that according to equations (4) - (7), the critical factor deciding for $\theta_{j}$ as the Condorcet Winner is not the strength of whichever actor (if any) most prefers $\theta_{j}$. The critical factor is the strength of the entire coalition advocating $\theta_{j}$ when compared with some other position (5). In fact, a position $\theta_{j}$ advocated by a comparatively weak actor with many strong allies could easily prevail against a position $\theta_{k}$ supported by a comparatively strong but isolated actor. The membership and strength of a coalition is affected by both intrinsic capability and the perceived stakes for each actor, which in turn are combined by the voting rule to estimate exercised influence (2).

When the winner of a Condorcet Election is determined strictly by (7), regardless of how small the margin of victory is, we refer to the winning option as the Deterministic Condorcet Winner. In many situations, this is too simplistic. When we model informal voting as the exertion of informal influence, the outcome is better represented as a probabilistic function of the ratio of coalition strengths; we'll come back to this.

\section{THE SPATIAL MODEL OF POLITICS AND MEDIAN VOTER THEOREM}

Due to cyclic group preferences, a dynamic CDMP model is not guaranteed always to have a Condorcet Winner; this requires the imposition of special conditions. One such framework that has been shown to guarantee existence of a Condorcet Winner is the Spatial Model of Politics (SMP); the SMP was introduced by Black [6], along with his Median Voter Theorem (MVT). The SMP and MVT ensure that a modeled CDMP will arrive at a Deterministic Condorcet Winner by imposing some basic conditions:

- The set of options $\Omega$ can be arranged on a line segment ([39] extends this to any number of dimensions).

- Proposals are made by actors called "office seeking politicians" and voted upon by "utility maximizers".

- Each utility maximizing actor has a unimodal utility function centered on its most preferred option that decreases monotonically elsewhere proportional to the distance from preference.

- The amount of influence a utility maximizing actor brings to bear through binary voting is a function of capability and stakes, as per (1).

- Preponderance of influence determines the winning option in a vote, as per (6).

While not every policy debate can be usefully modeled as a gradation between two extremes, a great many can. According to the experience cited in [20], thousands of political, military, and economic situations have been successfully analyzed using the spatial model of politics. An independent application of the one-dimensional spatial model of politics was used for detailed analyses of the entire voting history of the United States Congress; according to Poole and Rosenthal [27-30], the spatial model of politics was found to explain over $90 \%$ of congressional voting behavior.

Black's Median Voter Theorem is one of the most famous and widely used results in voting theory and analytical politics. It is 
widely used in both scholarly articles and popular political discussions. In this theorem, he developed the idea of the weighted median position which dominates all other options. He demonstrated, pursuant to some conditions, two crucial facts. First, there is a Deterministic Condorcet Winner which is the weighted median position. Second, a dynamic CDMP based on the SMP would converge to that Deterministic Condorcet Winner. It is critical for the weighted median position that an actor's vote between two options be an increasing function of the distance between options $\theta_{j}$ and $\theta_{k}$, and that actors prefer options closer to their own. Mathematically, this means that the utility to an actor is single peaked at its advocated position, and monotonically decreasing elsewhere.

Black describes an iterative process where there is a proposal, $z_{t}$, "on the floor" at each step, and actors propose amendments to it. The proposers are assumed to be "office seeking politicians", who seek to have their proposal adopted by "utility maximizing actors". As explained, the former will be motivated to propose amendments that dominate the current proposal and the dominant amendment will be selected. Mathematically, we can represent the iterative convergence of the CDMP toward the Deterministic Condorcet Winner, where $z_{t+1}$ is the amended proposal $z_{t}$, as

$$
z_{t+1}=\underset{\theta_{j} \in \eta\left(z_{t}\right)}{\operatorname{argmax}} V\left(\theta_{j}: z_{t}\right),
$$

where $\eta$ indicates a neighborhood of proposal similarity. Because only dominating proposals are ever accepted under the Median Voter Theorem, $z_{t}$ monotonically converges to the Deterministic Condorcet Winner, then the iterative process stops.

Unfortunately, the Median Voter Theorem does not generalize easily. Many cases in which we may want to quantitatively model a CDMP - notably for economic policy decisions - may have some or all of these characteristics:

- options can't be logically arrayed along a single-dimensional line

- actors' utility functions are neither unimodal, nor monotonically decreasing from their preferred option

- difference in utilities is not proportional to distance

[38] models a situation in which all of these characteristics arise. Policy makers negotiate a revenue-neutral package of by-sector taxes and subsidies, with a real economic model for actors' utilities. Instead of the SMP, the authors used a more complex model, part of which will be discussed in the next section.

Hence, while the SMP is an important framework and a fundamental concept which can be sometimes be generalized for more complex models, it is too constrained and simplistic for many applications.

\subsection{Nash Bargaining in the SMP}

Important modifications to the SMP have come from the models documented in [8, 9, 11-14, 32, 33, 37]. These models have incorporated concepts such as anchoring, prospect theory, and risk adjustment $[34,35]$. In particular, step (iii) in the algorithm at the beginning of Section 2 is expanded into four phases, through which every actor proceeds:

Assessment An actor whom we'll call the "proposer" assesses, from his own perspective, the potential support he could obtain from each other actor individually if he were to exert influence to persuade them to advocate a different position. This assessment is based on a subjective calculation of all other actors' preferences, as revealed in previous iterations of the CDMP.

Targeting Based on his assessments, the proposer determines the best actor, called the "target", to attempt to persuade. The optimal target is the actor who maximizes the increase in utility expected from the attempted persuasion, but also considers the expected change in utility to the target. In a truly strategic manner, the proposer also considers the strength of any coalition which may support him, and any coalition which the target may be able to form to rebuff a change in advocacy.

Proposal If the proposer was able to identify an optimal target, he must then propose a bargain. The bargain may specify new positions for both of them; since the target is likely to be weaker, the bargain will likely specify a larger move for the target. The proposal is a result of a Nash Bargaining Solution that takes into account the differing utilities and beliefs of the two actors.

Resolution Every actor may have potentially proposed a bargain to another actor - the steps of Assessment, Targeting, and Proposal conceptually happen simultaneously. Actors often receive many proposals, stored in a queue; the queue also contains any bargain the actor proposed, as well as the status quo of no change in his advocated position. Out of all these, however, an actor can acquiesce to at most one bargain. The resolution phase applies a Condorcet Election (with all actors voting) on all the proposed bargains in each actor's queue individually. The actor is forced to acquiesce to the bargain with the preponderance of influence - the Condorcet Winner. If a weak actor can rally enough third party support for its position, then it may not be forced to accept any proposal - the status quo, or even his proposal to a stronger actor, could end up the Condorcet Winner. Note the implication that, in this model, bargains are not binding. A proposed bargain could be the Condorcet Winner in either actors' queue, but not in the queue of the counterparty.

\section{PROBABILISTIC CONDORCET ELECTION}

By using (7), a Condorcet Election can result in a Condorcet Winner that is guaranteed to win, even by a very small margin. It may be appropriate for a committee vote of 11:10 resulting in the first option always being a clear winner. However, it is inappropriate for modeling informal negotiation situations that are based on influence, rather than votes. If two rival political campaigns each spent $\$ 10$ million to support their candidate, then each candidate would have a $50 \%$ chance of victory, all else being equal. If they could fund campaigns in the ratio 11:10, the first candidate would not be absolutely guaranteed of victory, though the probability would be raised somewhat above $50 \%$ - again, all else being equal. More general informal negotiation processes such as this are better modeled with the Probabilistic Condorcet Election (PCE) of [37], in which the probability of an option's winning is proportional to a function of the ratio of coalition strengths (note this is a different 
conception of probabilistic voting than that of, say, [17]). For a pair of options, $\theta_{j}$ and $\theta_{k}$, one rule for the probability that $\theta_{j}$ will be chosen over $\theta_{k}$ is that the probabilities depend on a simple ratio of strengths, as in the following:

$$
P\left[\theta_{j}>\theta_{k}\right]=\frac{s\left(\theta_{j}: \theta_{k}\right)}{s\left(\theta_{j}: \theta_{k}\right)+s\left(\theta_{k}: \theta_{j}\right)} .
$$

For the example of the rival political campaigns funded at the 11:10 ratio, this linear victory probability model would result in a $52 \%$ probability of success for the first campaign.

The PCE does not rely on any particular function for the winning probability (equation (9) is just one example). In particular, if the probability is $100 \%$ that the stronger coalition wins, no matter how small the margin, then the PCE replicates the standard deterministic Condorcet Election. Thus, PCE's are a proper superset of Deterministic Condorcet Elections.

The result of each iteration of negotiation is only dependent on the previous iteration, so the negotiation process is a Markov process. The limiting distribution of the Markov process gives the likelihood that each option is the winner at any given turn of the CDMP. For the trivial case of a state with just two options $S=$ $\left(\theta_{j}, \theta_{k}\right)$, and linear transition probabilities, the limiting distribution is exactly the intuitive result:

$$
\begin{aligned}
& P\left[\theta_{j} \mid S\right]=\frac{s\left(\theta_{j}: \theta_{k}\right)}{s\left(\theta_{j}: \theta_{k}\right)+s\left(\theta_{k}: \theta_{j}\right)}, \\
& P\left[\theta_{k} \mid S\right]=\frac{s\left(\theta_{k}: \theta_{j}\right)}{s\left(\theta_{j}: \theta_{k}\right)+s\left(\theta_{k}: \theta_{j}\right)} .
\end{aligned}
$$

For the case of two options, the Deterministic Condorcet Winner will have the stronger coalition and hence also the highest probability.

As with the original Condorcet Election, we compute the votes and coalition strengths for all pairs of options in the state $S$. The pairwise transition probabilities $P\left[\theta_{j}>\theta_{k}\right]$ are then used to compute the conditional probability for each option $P[\theta \mid S]$, and the option $\theta_{j}$ with the highest probability is deemed the Probabilistic Condorcet Winner:

$$
\theta_{j}=\underset{\forall \theta \in S}{\operatorname{argmax}} P[\theta \mid S]
$$

The Probabilistic Condorcet Winner has important similarities to a Deterministic Condorcet Winner, as well as some useful differences. As shown above, the Deterministic Condorcet Winner and Probabilistic Condorcet Winner are identical for a choice between two options. For a wide variety of problems - one-dimensional spatial model, multidimensional spatial model, discrete combinatorial with random utilities, and so on - with proportional voting, the coalition structure can be computed so as to determine both the Deterministic Condorcet Winner and the Probabilistic Condorcet Winner. Almost always, the Probabilistic Condorcet Winner will be the Deterministic Condorcet Winner. There are still important differences, though:

- Depending on the type of model and voting rule, a Deterministic Condorcet Winner might not exist, whereas the limiting distribution for the PCE Markov process will. This is true even when different probabilistic transition models are allowed.
- Along with the winning option, which is a point estimate, the PCE provides an indication of the dispersion of plausible results around that estimate.

The Probabilistic Condorcet Election is a general framework for modeling informal CDMPs; this framework is extremely flexible, and lacks restrictive assumptions present in others. Indeed, a typically deterministic form of a spatial model of politics can gain these properties by simply using proportional voting plus a victory probability model in the form of (9).

\section{KAPSARC TOOLKIT FOR BEHAVIORAL ANALYSIS}

The KAPSARC Toolkit for Behavioral Analysis is an open-source platform under development by the King Abdullah Petroleum Studies and Research Center to meet the need for widely available, state-of-the-art, supported, transparent, and open-source software that facilitates simulation modeling and rigorous analysis of CDMPs - predominantly under the paradigm of the PCE. While KTAB does currently include several example CDMP models, it is not itself a model, but a platform for building models. It is a CDMP simulator that can be used to generate insight into a wide variety of types of collective decision-making. This platform is designed to enable a broad range of analysts to generate their own insights, and hopefully extend the awareness of computer models as a route to the investigation of CDMPs.

The $\mathrm{C}++$ software libraries and source code for KTAB are released as open-source under the MIT license, and reside on github at http://kapsarc.github.io/KTAB/. One of the sample models included in KTAB is a multi-dimensional PCE-based generalization of the SMP [39]. This example application is currently compilable under both Windows and Linux into three forms: a GUI-based application, a console-based application, and a dynamically- linkable library. This last item is new and especially exciting, as it will allow non- $\mathrm{C}++$ developers to access the underlying CDMP algorithms with other languages; KTAB currently includes an example of how to do this with python. We encourage international collaboration on KTAB, and have had contributors as far west as the USA and as far east as India (with respect to Saudi Arabia).

KTAB has been used to generate insights with both spatial and non-spatial CDMP models in a variety of case studies including:

- Energy sector policy reform in China: [18]

- Policy to facilitate transition to less carbon intensive energy system in the United Arab Emirates: [19]

- Policy formulation to facilitate optimized agricultural water use for sustainability in Saudi Arabia: [24]

In the next section, we summarize results and insights from the latter two case studies. For more details, please see the cited sources.

\section{NUMERICAL RESULTS}

Here we document results of CDMPs simulated and analyzed with $\mathrm{KTAB}$ on two separate case studies regarding important energyrelated policy questions in the Arab Gulf region. The first uses an SMP, while the second uses a PCE-based non-spatial model, which we may call an Enumerated Model of Politics. 


\subsection{Developing Policy to Facilitate Transition from Carbon-Intensive Energy Generation}

The fundamental question addressed is: "What is the political feasibility in the United Arab Emirates for implementing different policy options available to decision makers that may help drive a transition to a lower carbon energy system?"

The United Arab Emirates (UAE) is a federation of seven constituent emirates: Abu Dhabi, Ajman, Dubai, Fujairah, Ras al-Khaimah, Sharjah, and Umm al-Quwain. Under the UAE government system, the President of the Federation is elected by a Supreme Council of Rulers, which is the top policy-making body in the UAE. The UAE Vice President is also elected by the Supreme Council and both the President and Vice President serve renewable five-year terms. Notably, the UAE President is also Commander of the UAE Armed Forces, Chairman of the Supreme Council and Chairman of the Supreme Petroleum Council. Regarding energy governance, each UAE emirate constitutionally maintains considerable power over its own energy sector governance, including control over mineral rights (most notably oil) and governance of the power and water sector. Although the UAE federal government has exclusive and executive jurisdiction over electricity services, in practice each emirate formulates and implements its own electricity policies and operates essentially independently.

In October 2015, the UAE's federal Ministry of Foreign Affairs submitted its Nationally Determined Contributions to the United Nations Framework Convention on Climate Change in advance of the COP21 Meeting in Paris. The document set a target of increasing the clean energy contribution to the UAE's total energy mix from $0.2 \%$ in 2014 to $24 \%$ by 2021 . Furthermore, it outlined additional economic diversification and sustainability efforts. However, the ministry neglected to commit to a specific level of carbon emissions reduction. More recently in 2017, the UAE Ministry of Energy announced their "UAE Energy Strategy 2050" that outlines a number of energy targets for 2050 (UAE Ministry of Energy, [36]):

- Power: $44 \%$ of electricity from renewable energy, $38 \%$ from natural gas, $12 \%$ from clean fossil, and $6 \%$ from nuclear energy

- Energy Efficiency: $40 \%$ improvement relative to current annual growth in electricity demand of $6 \%$

- Carbon Emission Reduction: 70\% reduction in carbon emissions from power generation

As with the 2015 Nationally Determined Contributions, this energy strategy contains general ambitions and aspirational targets for sustainable national development but doesn't lay out precisely how the ambitions and targets will be achieved.

One reason for this, if not the over-arching one, is the UAE's complex decision-making process that results from the fact that the country is a federation of seven nominally independent emirates. Power is polarized between Abu Dhabi and Dubai, which historically strictly guard their policy-making independence. The remaining smaller emirates, known collectively as the Northern Emirates, tend to follow Abu Dhabi's policy lead.

For the purposes of this study, the authors identified six policy instruments to measure the energy system transition:

1. Carbon Pricing: implementation of a carbon-focused tax, or related policy measures, that directly impose a price on carbon
2. Renewables: increased deployment of renewable energy sources (e.g. solar and/or wind) for electric power generation and desalination

3. Nuclear Energy: implementation of already planned deployment of nuclear energy in electric power generation

4. Energy Efficiency (EE): increased implementation of EE standards with monitored performance and audits to achieve greater EE technology adoption and demand-side management

5. Energy Subsidy Reform: further reform of energy subsidies for power, water, and transportation fuels

6. Natural Gas: maintain the use of natural gas in electric power generation, perhaps taking advantage of new sources of cheap gas (e.g. LNG) or new gas field development

The previously-mentioned complexities of the UAE political system add a layer of difficulty to the implementation of these six policy instruments, which require consideration of several competing aspects [21].

This problem was analyzed as six separate SMPs with political support for each policy instrument measured on a continuous spectrum, from Fully Opposed to Fully Supportive, as shown in Figure 1.

\begin{tabular}{cccc} 
Fully Opposed & Neutral & Fully Supportive \\
\hdashline 0 & 50 & 100
\end{tabular}

Figure 1: Spectrum of Actor Support Used for Each Policy Instrument

Data for the analysis was gathered by structured interviews with experts who are knowledgeable about the key actors - those with the ability to influence the decisions regarding each of these policy alternatives. For each actor, the data gathered (per dimension) included their capability $C_{i}$, initially-advocated position $\theta_{i 0}$, and salience $S_{i}$. All this information taken together can be used to infer the current consensus view (if any) on the support for, or opposition to, each of the six policy instruments. The data is shown in Table 1; grouping codes are not used by the model, but are there to facilitate generating insights into the actors' behavior.

The KTAB SMP is used to simulate the interactions of actors over over several iterations of negotiation and bargaining. Nothing about the SMP requires that actors actually reach consensus - they could very well not agree. However, the positions of actors at the end of the simulation allows us to draw some inferences as to the political feasibility of the particular policy option. When consensus is achieved, we can say that a policy option is "politically feasible". When there is no consensus achieved, or when the consensus is in opposition to that particular policy option, we can say that it is "politically infeasible". When consensus emerges from the simulation, the nature of that consensus informs what form of the policy is feasible. In other words, if most of the actors end the simulation clustered around a position that is near a position of 100 , we can infer that there is a consensus in favor of a strong and enforceable version of the policy. If actors end the simulation clustered around a position that is closer to neutral, then we can infer that there is a consensus in favor of a weakly constructed, and more symbolic version of the policy. 
Table 1: Expert-Based Data Regarding Support for or Opposition to UAE Energy Transition Policy Options: (P)osition, (C)apability, (S)alience. Actor group codes are: $\mathrm{R}=$ Royal Family, G = Government, EC = Energy Company, A = Advisor, ECC = Energy Consuming Company

\begin{tabular}{|c|c|c|c|c|c|c|c|c|c|c|c|c|c|c|c|c|c|c|}
\hline \multirow[b]{2}{*}{ Actor - Group } & \multicolumn{3}{|c|}{ Carbon Pricing } & \multicolumn{3}{|c|}{ Renewables } & \multicolumn{3}{|c|}{ Nuclear Power } & \multicolumn{3}{|c|}{ Energy Efficiency } & \multicolumn{3}{|c|}{ Price Reform } & \multicolumn{3}{|c|}{ Natural Gas } \\
\hline & $\mathrm{P}$ & $\mathrm{C}$ & $\mathrm{S}$ & $\mathrm{P}$ & $\mathrm{C}$ & $\mathrm{S}$ & $\mathrm{P}$ & $\mathrm{C}$ & S & $\mathrm{P}$ & $\mathrm{C}$ & $\mathrm{S}$ & $\mathrm{P}$ & $\mathrm{C}$ & S & $\mathrm{P}$ & $\mathrm{C}$ & S \\
\hline Abu Dhabi Crown Prince - RF & 50 & 100 & 10 & 80 & 100 & 22.5 & 100 & 100 & 35 & 62.5 & 100 & 12.5 & 75 & 100 & 35 & 62.5 & 100 & 10 \\
\hline Prime Minister - RF & 60 & 85 & 20 & 90 & 82.5 & 25 & 67.5 & 52.5 & 20 & 72.5 & 87.5 & 13.5 & 80 & 87.5 & 20 & 72.5 & 85 & 22.5 \\
\hline Abu Dhabi Executive Council - G & 20 & 70 & 10 & 50 & 60 & 17.5 & 100 & 75 & 15 & 50 & 70 & 10 & 55 & 60 & 17.5 & 55 & 55 & 16.5 \\
\hline Min. of Energy - G & 60 & 30 & 25 & 70 & 35 & 37.5 & 70 & 25 & 27.5 & 75 & 35 & 20 & 75 & 32.5 & 20 & 55 & 52.5 & 27.5 \\
\hline Min. of Climate Change and Env.t - G & 80 & 20 & 40 & 90 & 35 & 50 & 60 & 20 & 32.5 & 95 & 25 & 32.5 & 90 & 17.5 & 35 & 55 & 12.5 & 40 \\
\hline Min. of State - G & 0 & 50 & 15 & 80 & 55 & 22.5 & 75 & 40 & 16 & 65 & 45 & 17.5 & 85 & 30 & 12.5 & 57.5 & 35 & 17.5 \\
\hline Min. of Finance - G & 50 & 20 & 5 & 50 & 20 & 3.5 & 47.5 & 25 & 13.5 & 40 & 50 & 3.5 & 75 & 40 & 22.5 & 70 & 40 & 15 \\
\hline Min. of Foreign Affairs - G & 75 & 60 & 5 & 70 & 35 & 10 & 60 & 40 & 12.5 & 47.5 & 45 & 5 & 60 & 32.5 & 5 & 60 & 35 & 5 \\
\hline Mubadala - EC & 60 & 60 & 10 & 70 & 60 & 12.5 & 85 & 70 & 17.5 & 50 & 50 & 9.5 & 80 & 45 & 10 & 55 & 45 & 12.5 \\
\hline Executive Affairs Auth. - G & 60 & 10 & 10 & 70 & 20 & 27.5 & 100 & 75 & 45 & 75 & 37.5 & 45 & 87.5 & 12.5 & 35 & 52.5 & 35 & 37.5 \\
\hline Regulation and Supervisory Bureau - G & 55 & 10 & 15 & 70 & 15 & 20 & 60 & 15 & 22.5 & 90 & 10 & 47.5 & 100 & 37.5 & 57.5 & 75 & 5.5 & 45 \\
\hline Abu Dhabi Water and Electricity Auth. - G & 60 & 30 & 15 & 60 & 25 & 17.5 & 60 & 25 & 15 & 80 & 30 & 40 & 70 & 50 & 47.5 & 77.5 & 30 & 52.5 \\
\hline Emirates Nuclear Energy Corp. - EC & 80 & 5 & 5 & 40 & 7.5 & 3.5 & 100 & 40 & 69.5 & 57.5 & 2.5 & 3.5 & 45 & 2.5 & 11 & 45 & 17.5 & 3 \\
\hline Env.tal Agency - Abu Dhabi - A & 80 & 20 & 40 & 100 & 35 & 45 & 50 & 20 & 32.5 & 90 & 22.5 & 37.5 & 85 & 15 & 40 & 35 & 15 & 40 \\
\hline Masdar - EC & 75 & 5 & 30 & 100 & 40 & 35 & 45 & 27.5 & 65 & 70 & 15 & 25 & 57.5 & 22.5 & 22.5 & 42.5 & 5 & 20 \\
\hline TAQA (Abu Dhabu Natl. Energy Co.) - EC & 20 & 2 & 20 & 80 & 1.5 & 12.5 & 45 & 1.5 & 17.5 & 57.5 & 1.5 & 17.5 & 45 & 3.5 & 8 & 87.5 & 1.5 & 47.5 \\
\hline Supreme Petroleum Council - G & 20 & 50 & 5 & 50 & 60 & 5 & 50 & 50 & 7.5 & 65 & 65 & 5 & 50 & 65 & 32.5 & 55 & 70 & 17.5 \\
\hline Dubai Supreme Council of Energy - G & 65 & 30 & 15 & 90 & 40 & 42.5 & 50 & 20 & 36 & 75 & 30 & 35 & 90 & 35 & 35 & 65 & 35 & 44.5 \\
\hline Dubai Electricity and Water Auth. - G & 65 & 30 & 30 & 90 & 40 & 52.5 & 42.5 & 20 & 35 & 75 & 45 & 47.5 & 90 & 37.5 & 45 & 60 & 45 & 47.5 \\
\hline Sharjah Electricity and Water Auth. - G & 20 & 5 & 2 & 50 & 12.5 & 33.5 & 35 & 10 & 32.5 & 65 & 3 & 34.5 & 90 & 5 & 42.5 & 67.5 & 12.5 & 52.5 \\
\hline Federal Electricity and Water Auth. - G & 50 & 2 & 2 & 60 & 1.5 & 32.5 & 35 & 6 & 35 & 62.5 & 1.5 & 32.5 & 95 & 1.5 & 45 & 60 & 1.5 & 52.5 \\
\hline UAE Central Bank - G & 70 & 2 & 5 & 60 & 6 & 3 & 35 & 11 & 8.5 & 50 & 26 & 3 & 75 & 26 & 22.5 & 65 & 1.5 & 5 \\
\hline Abu Dhabi Natl. Oil Co. (ADNOC) - EC & 0 & 45 & 20 & 60 & 37.5 & 7.5 & 50 & 27.5 & 5 & 50 & 42.5 & 5 & 55 & 42.5 & 22.5 & 45 & 57.5 & 32 \\
\hline Dolphin Energy - EC & 0 & 10 & 5 & 30 & 5.5 & 10 & 35 & 5.5 & 3.5 & 50 & 5.5 & 3 & 42.5 & 20 & 20.5 & 100 & 22.5 & 67.5 \\
\hline Civil society org's (pro-Env.t) - A & 100 & 4 & 40 & 100 & 7 & 37.5 & 35 & 4.5 & 39.5 & 100 & 2.5 & 49.5 & 90 & 4.5 & 40 & 55 & 2.5 & 42.5 \\
\hline Energy intensive industrials - ECC & 10 & 40 & 10 & 60 & 20.5 & 11 & 45 & 40 & 17.5 & 50 & 20.5 & 12.5 & 20 & 32.5 & 50 & 80 & 32.5 & 35 \\
\hline Aviation industry - ECC & 0 & 70 & 40 & 50 & 20 & 10 & 50 & 20 & 10 & 50 & 20 & 40 & 0 & 20 & 40 & 50 & 20 & 10 \\
\hline
\end{tabular}

Results of the simulations are shown graphically in Figures 2-7; each figure is a controllable animation of three images. For each policy instrument, we show a Sankey Diagram of all iterations of the simulated CDMP. Each line represents an actor's advocated position over time, and the color of the line represents the intensity of their support / opposition (red / blue). Each figure also displays two bar charts of combined coalition strength for actors advocating similar positions along the spectrum of political support. The first chart is their initial advocacy (from the expert-elicited data), and the second is from the end of the simulated CDMP. Each figure caption indicates in parentheses the number of iterations until the simulation converged. From these figures, we can glean several insights into the political feasibility of a successful transition to a less carbon-intensive energy system in the UAE.

Firstly, observe the pattern of coloration at the end of the simulated CDMP for each policy instrument. There is very strong support for increased deployment of renewable generation and implementation of already planned nuclear energy generation. These policy instruments are likely to be political successes. With the exception of the unwavering support of the Executive Affairs Authority, there is mostly moderate support for increased implementation of energy efficiency standards, as well as continued reliance on natural gas. Energy subsidy reform is only slightly less politically feasible. Perhaps unsurprising, the preponderance of political will is in slight opposition to implementing a carbon pricing system, with complete steadfast opposition from some energy consuming companies. Reviewing the CDMP simulation results in more detail, we can glean several more insights:
- Initially, actors spanned the entire spectrum of support for, or opposition to, implementation of a carbon pricing scheme. Energy consuming companies oppose this policy instrument for obvious reasons. On the supportive end of the spectrum are the environmental advisory agencies. The simulation required 15 iterations to converge, which is relatively long, indicating a somewhat protracted debate. Energy companies ADNOC and TAQA quickly formed a coalition with the Prime Minister advocating weak opposition, around which consensus coalesced. Due largely to their weaker influence and inability to form a supporting coalition, the environmental agencies were forced to acquiesce and join this consensus, in order to give the appearance of being team players. As can be seen in the Sankey diagram, there are several actors vacillating between positions. This behavior in the simulation suggests that they are less concerned with finding support for an outcome they prefer, and more concerned with finding a consensus to which everyone can agree. At the end, only the aviation industry maintained their staunch opposition to a carbon price. Implementing a carbon pricing scheme in the UAE is likely politically infeasible.

- Results from analyzing feasibility of an increase in renewables are perhaps the most surprising, in that the decisionmaking process took the longest of all 6 analyses. Besides the fact that renewables represent no clear and present danger to any of the actors, the spread of initially advocated positions is almost entirely on the supporting half of the spectrum. Only two actors - a gas and nuclear energy company - advocated slight opposition. Neither were willing or even able 
to hold out in opposition; not only are they very weak and unlikely to attract a coalition, both gas and nuclear can be complements to intermittent renewable generation. While the kernel of a consensus quickly formed around the Crown Prince and Prime Minister in strong support, we again observe some back-and-forth involved in consensus building (observe the lower orange band on the Sankey plot waning as the upper waxes). There is likely to be increasingly robust political will in support of renewable energy in the UAE.

- Initially, there was only slight opposition to the planned deployment of nuclear power generators. Perhaps the opposition views nuclear power as marginally-negative at worst. To the extent opponents will seek to derail the progress on nuclear power in the UAE, this could indicate a strategy of delay rather than clear opposition. Recent events seem to support this hypothesis. While the construction appears to be on track for start-up of the Barakh power plant, the local operating company, Nawah, has been delayed in obtaining an operating license [15]. The only other interesting point observable in the results is the continued neutrality of Masdar Institute. Despite recent setbacks, the political will for nuclear power in the UAE as part of the energy transition strategy appears to be very robust.

- Those actors initially not in favor of energy efficiency are either weakly-opposed or neutral, suggesting they oppose the timing and scope of any changes rather than the underlying principle. By the end of the simulation, there is consensus in favor of a moderately strong energy efficiencybased approach. The Executive Affairs Authority continued to advocate for full support of energy efficiency throughout the simulated CDMP. While the pro-environment Civil Society Organizations initially advocated full support also, they quickly defected to a moderately supportive position. We can infer from these figures that the current support for energy efficiency is likely to strengthen over time. Disagreements about the scope and timing should be minimized to facilitate and accelerate implementation of policies that enjoy consensus support.

- As with implementation of carbon pricing, the energy consuming companies initially advocated a position of strong opposition to energy subsidy reform. As before, the energyintensive industrials were less opposed than the aviation industry. Input energy is a smaller portion of their production costs, so a dramatic increase in prices would hurt them less than it would hurt the airlines. With the exception of these actors, the distribution of political will began markedly positive, with a peak anchored by the Crown Prince and Prime Minister advocating strong support. Despite their initiallystronger advocacy, they were willing to make concessions to consolidate the support of industry. Indeed, we see this at the end of the simulation, as a strong consensus has coalesced around weak support of price subsidy reform. The energy consuming companies moderated their opposition and joined the consensus, likely to help shape the form of any policies to best align with their own interests. The Regulator remained a strong advocate for price subsidy reforms. There appears to be the political will to undertake price reform in the UAE as part of its energy transition strategy, but the scope and magnitude of potential reforms may not be very significant.

- The CDMP simulation began with mostly support for maintenance of natural gas in the energy mix, centered around the advocacy of the Crown Prince. Only the environmental advisory organizations were in weak opposition. The simulation required 15 iterations to converge, indicating an oddlyprotracted debate. A coalition eventually formed around the Prince's original position of weak support, with only a few actors advocating stronger support. One of these is Dolphin Energy; note that the model does not know Dolphin is a gas company, it simply knows that this actor cares more than any other actor. Indeed, a challenge to keeping gas in the energy mix is a direct challenge to their business; regrettably for Dolphin, they are not sufficiently influential to attract a coalition to their advocated position of full support. Thus, we can infer from the simulation results that the political will for maintenance of natural gas in the UAE should coalesce to a weakly positive position.

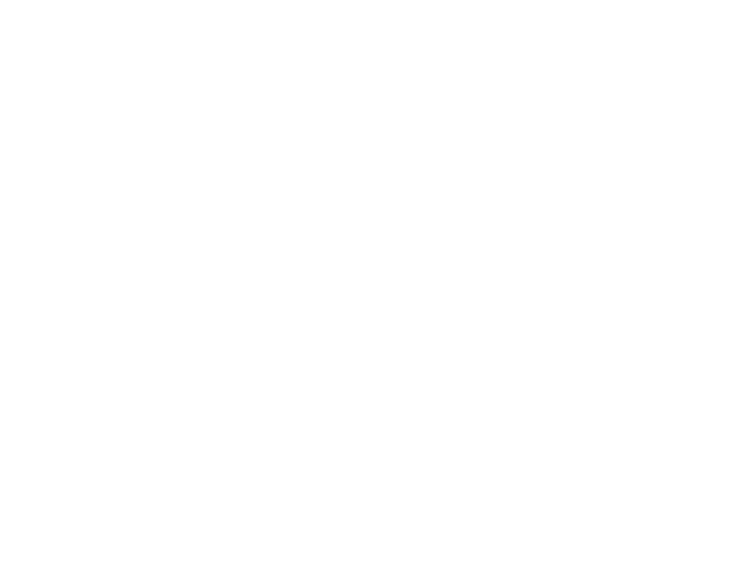

Figure 2: Carbon Pricing Feasibility (15)

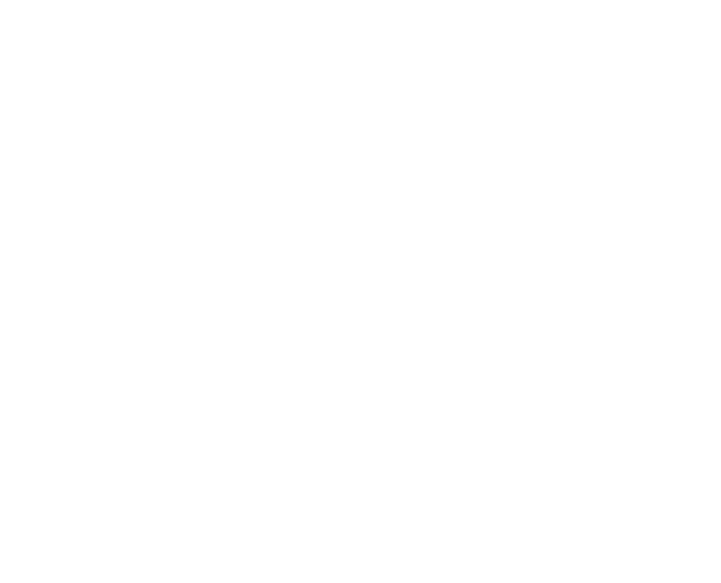

Figure 3: Renewables Feasibility (20) 


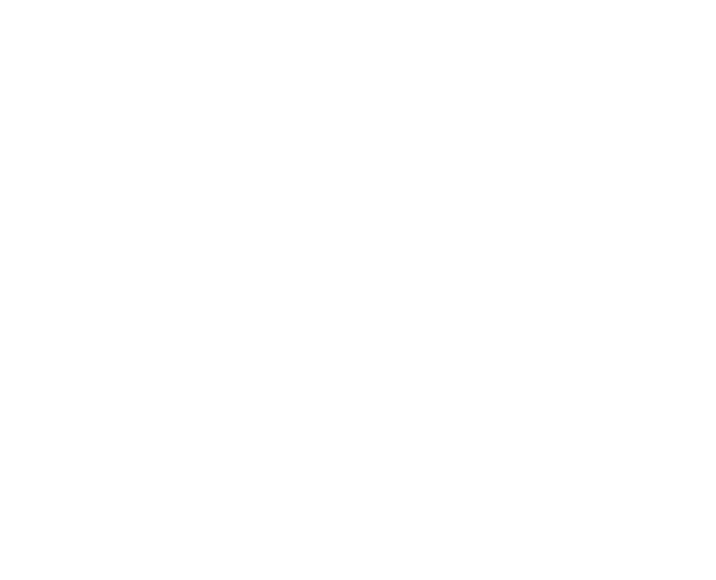

Figure 4: Nuclear Power Feasibility (11)

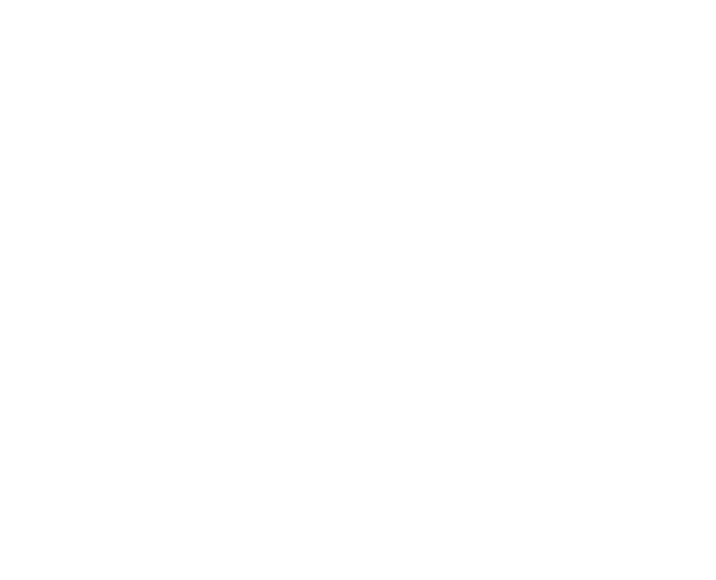

Figure 5: Energy Efficiency Feasibility (12)

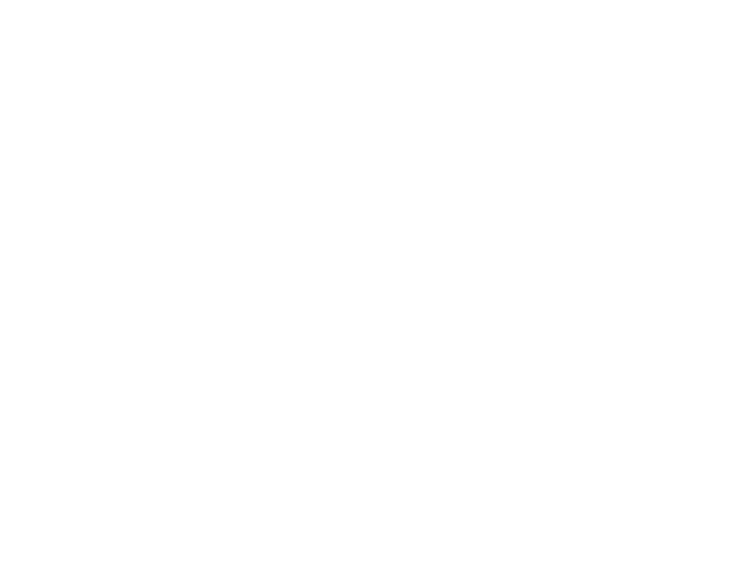

Figure 6: Energy Subsidy Reform Feasibility (11)

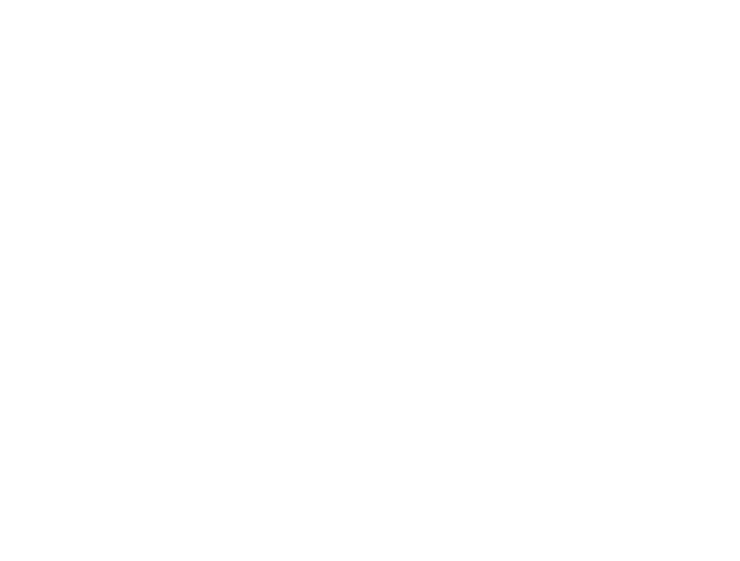

Figure 7: Natural Gas Feasibility (15)

\subsection{Minimizing Agricultural Water Use to Optimize Sustainability}

The fundamental question addressed is: "Can we find (and hence develop policy to facilitate) an optimal mix of agricultural products that balance water sustainability, food supply security, and agricultural sector revenue stability?"

According to Brown and Matlock [7], a country that withdraws more than $40 \%$ of its total renewable water resources annually is considered to be severely water scarce. Saudi Arabia, then, is a severely water scarce country as it is withdrawing an astounding $1,056 \%$ of its total renewable water resources. This means that the country is not only relying on renewable water resources, but is also drawing heavily from nonrenewable fossil aquifers. Improving water sustainability is an important environmental concern in the Kingdom of Saudi Arabia. Further, much of the water comes from desalination, which is an energy-intensive process. Thus, any reduction in water consumption could also lead to significant energy savings.

Approximately $87 \%$ of water extracted is used for agriculture, so no policy to improve the sustainability of water resources can ignore this industry. Saudi Arabia's extreme water scarcity makes it a sub-optimal location for agricultural production. Despite this, the rationale for supporting a domestic agriculture industry is twofold. First, the country is attempting to safeguard its food security by ensuring that an adequate amount of diverse foods is produced locally [23]. For certain fruit, vegetables, and cereals, food self-sufficiency goals were met and the country exports surplus production [2]. The Food and Agriculture Organization estimates that Saudi Arabia's total aggregated agriculture self-sufficiency ratio is roughly $25 \%{ }^{1}$. The second reason for supporting domestic agriculture production is that the agriculture industry is politically and socially sensitive. Agriculture provides employment and income, and certain agricultural products are culturally significant, such as dates. Almost a third of water consumed by agriculture is used to grow alfalfa and other livestock fodder; fruits, vegetables, and cereals account for $35 \%$ of usage. The growth of dates alone uses $13 \%$. The government

${ }^{1}$ http://faostat.fao.org, Accessed August 2015 
supports the agriculture industry with a range of implicit and explicit subsidies to ensure profitability, despite the fact that it may be unsustainable in the long term.

The government of Saudi Arabia has recognized the unsustainability of the rate of current water consumption, and has responded with several policies to increase importation of certain foodstuffs. Moreover, in 2010 the Ministry of Agriculture set a target of a $30 \%$ reduction in water usage in the agriculture sector by 2030 by improving irrigation techniques and eliminating water intensive crops; this target may be increased to $50 \%$, according to Jeffreys [22]. The question remains about how to develop policy that will facilitate such dramatic reductions in agricultural water consumption, while balancing the competing interests of food supply security and agricultural sector revenue stability. This analysis proceeded in two steps. The first was to define a mathematical model to optimize crop production mix while reducing water consumption. The second step is to use this data to inform a CDMP model of how agricultural representatives would negotiate to define an appropriate public policy.

Initially, the authors constructed a linear program to analyze the trade-offs in water consumption in the agriculture and livestock sectors for a range of policy scenarios; a linear programming model was chosen to provide a first-order assessment of how the agriculture system balances three primary components: water consumption, revenue, and total quantity produced. Data for these components are readily available at the national aggregate level and provide sufficient insight into the effect of different crop portfolios on water consumption. Because there are many subsidies to ensure that products sell at desired prices, rather than at competitive market prices, input prices were not included as part of the decision to produce a crop or not. The linear program, which minimizes water consumption, is

$$
\begin{aligned}
& \min _{w} \sum_{i} Q_{i} \times w_{i} \text { subject to } \\
& \sum_{i} Q_{i}^{0} \times P_{i}^{0} \leq \sum_{i} Q_{i} \times P_{i} \\
& \sum_{i} Q_{i}^{0} \leq \sum_{i} Q_{i} \\
& \quad\left(1-r_{i}\right) \times Q_{i}^{0} \leq Q_{i} \\
& Q_{i} \leq\left(1+g_{i}\right) \times Q_{i}^{0} \\
& \sum_{\text {fodder }}\left(Q_{\text {fodder }} * f\right) \geq \sum_{\text {livestock }} Q_{\text {livestock }}
\end{aligned}
$$

In this model, $Q_{i}$ is the production in tons of the $i^{\text {th }}$ crop, $w_{i}$ is the water needed, and $P_{i}$ is the price per ton paid to farmers. The $Q_{i}$ and $P_{i}$ variables are baseline case quantities and prices. The first and second constraints ensure sufficient farming revenue and sufficient aggregate domestic production. The next two equations constrain how much production of each product can decrease $\left(r_{i}\right)$ or increase $\left(g_{i}\right)$. The final constraint ensures enough fodder is grown to meet the demand for livestock (so an increase in livestock also increases fodder grown).

Ten scenarios were designed to explore the behavior of the system. These are shown in Table 2. The scenarios define three possible options for wheat, dairy, and dates: fixed, variable, and eliminated.
A crop cannot increase or decrease in production if it is fixed. If a crop is variable, its production is allowed to vary within the production bounds set in the model (first two columns of Table 2), just like any other crop. Production is set to zero if a crop is eliminated. Other crops are varied by the linear program. The fodder requirement of 0.81 indicates 81 tons of livestock can be fed from 100 tons of domestically-grown fodder. Scenarios with the 0.91 requirement indicated 10 more tons of livestock can be fed because some fodder is imported.

Results from optimizing the linear program over each of the 10 scenarios are displayed in Figure 8. The numerical output from the linear program for each scenario is a vector of total revenue to farmers of each crop, as well as the volume of each crop produced.

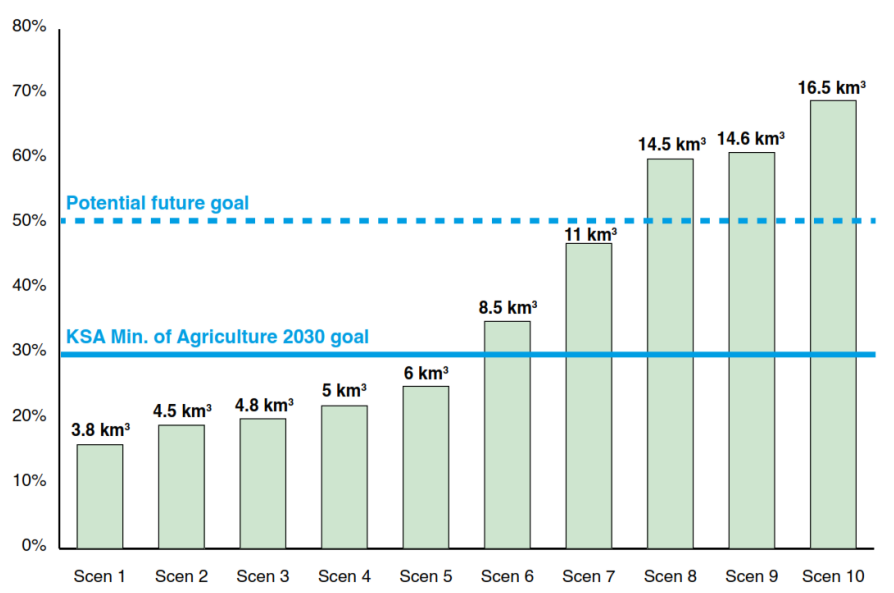

(a) Potential Reduction in Water Consumption

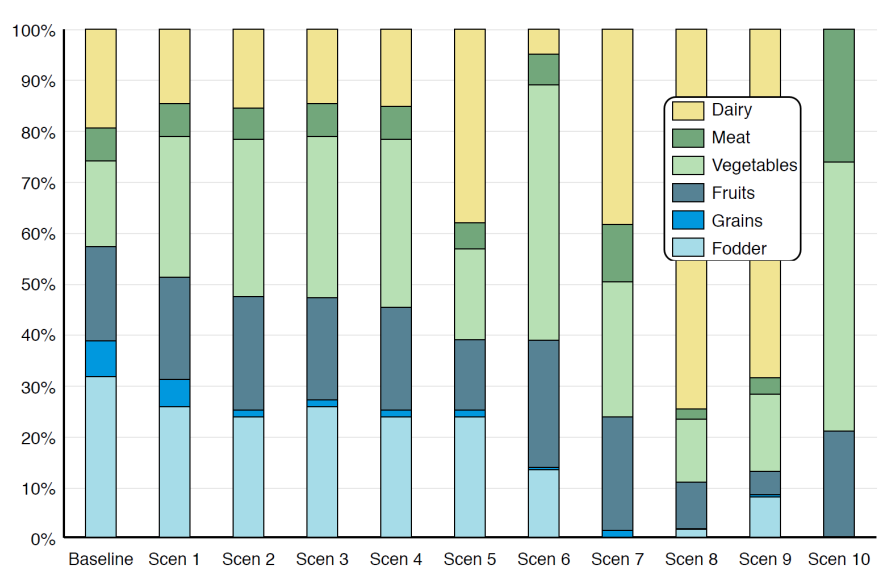

(b) Optimal Crop Mix

Figure 8: Results from Optimizing (11), by Scenario

Having determined the water consumption and revenue impacts from various scenarios of a modified agricultural production mix, the next step is to use this information in a CDMP model to determine the level of consensus supporting each of the ten scenarios. Scenarios with the strongest supporting coalitions and most 
Table 2: Policy Scenarios Modeled

\begin{tabular}{c|cccccc}
\hline Scenario & $\begin{array}{c}\text { Production } \\
\text { Decrease } \%\end{array}$ & $\begin{array}{c}\text { Production } \\
\text { Increase } \%\end{array}$ & $\begin{array}{c}\text { Fodder } \\
\text { Requirement }\end{array}$ & Wheat & Dairy & Dates \\
\hline 1 & 25 & 100 & 0.81 & Variable & Variable & Variable \\
2 & 25 & 100 & 0.91 & Eliminated & Variable & Fixed \\
3 & 25 & 100 & 0.81 & Eliminated & Variable & Variable \\
4 & 25 & 100 & 0.91 & Eliminated & Variable & Variable \\
5 & 25 & 100 & None & Eliminated & Variable & Variable \\
6 & 75 & 200 & 0.81 & Eliminated & Variable & Fixed \\
7 & 25 & 100 & Eliminated & Eliminated & Variable & Fixed \\
8 & 95 & 300 & None & Eliminated & Variable & Fixed \\
9 & 75 & 300 & None & Eliminated & Variable & Variable \\
10 & 95 & 300 & Eliminated & Eliminated & Eliminated & Variable \\
\hline
\end{tabular}

consensus are most likely to be politically feasible and practically implementable. This problem is not a very natural fit for a spatial model of politics. We could perhaps consider a multidimensional SMP in which each dimension represents the change in a crop. Most actors would care almost entirely about their crop dimension, and care very little about any others. Further, since there would be a dimension for each actor, it would likely be an ill-posed problem. The authors instead used a non-spatial CDMP model based on the PCE, following [37], in which actors representing the various agricultural sectors negotiate and bargain around each of the ten modeled scenarios. To represent the goal of reducing water consumption, an actor was added representing water reduction. Recall from Section 2 that an actor's vote is a function of of both utility and influence (see (1) and (2)).

One obvious candidate for this utility function is the revenue in each agricultural sector (output from the linear program), and the percentage revenue lost due to water reduction. To achieve the von Neumann utility scale, revenues were rescaled from raw values so that the scenario with the lowest revenue has value 0 and the best has value 1 . This is shown for the $i^{\text {th }}$ actor and scenario $s$ in (12), with $j$ indexing the scenarios.

$$
V_{i}(s)=\frac{R_{i}(s)-\min _{j} R_{i}\left(s_{j}\right)}{\max _{j} R_{i}\left(s_{j}\right)-\min _{j} R_{i}\left(s_{j}\right)}
$$

As is well-known from finance, actors are always risk-averse to one degree or another when nontrivial amounts are at stake: they demand a positive risk premium to compensate for exposure to more risk, even when the expected value stays constant. It is wellknown that as the risk of an investment increases, the interest rates on financing it also increase, which again reflects risk-aversion. Mathematically, this corresponds to a utility curve which is increasing, but at a decreasing rate. One simple way to model the utility function $U(s)$ is with a simple quadratic curve that matches the end points at 0 and at 1 . Hence the utility function is:

$$
U_{i}(s)=1-\left(1-V_{i}(s)\right)^{2} .
$$

A standard first estimate of an actor's influence is the net wealth controlled by that actor. These weights are often called Negishi weights [25]. While there is a debate as to whether these weights should be used in normative analysis, there is little debate that wealth and power are positively correlated. Therefore, the baseline revenue for each agricultural sector was used as an initial estimate of influences. However, this gives no influence to water reduction, and it also does not take into consideration the stated goals and relevant policies already announced by the government. For example, at the time this research began, wheat production was in the process of being eliminated, suggesting a very low level of influence to protect wheat production. The intention to reduce fodder and alfalfa was also announced shortly thereafter. Furthermore, the weights need to reflect the fact that certain culturally-important crops, such as dates, are likely carry influence not strictly related to revenue. Hence, the revenue-based Negishi weights were minimally tuned to be consistent with these facts.

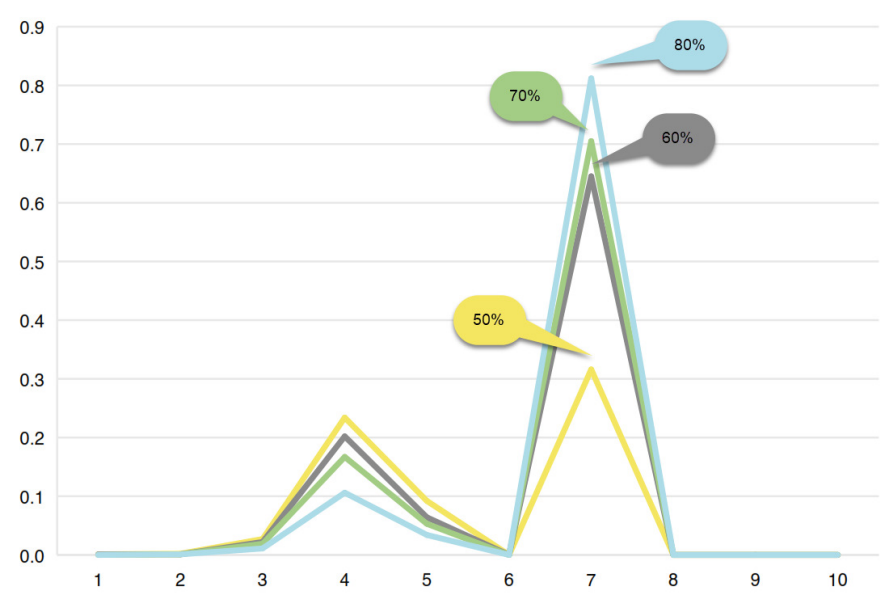

Figure 9: Sensitivity of Achievable Water Reduction to Changes in Importance of the Goal of Water Reduction

Figure 9 shows the political feasibility of each of the ten scenarios. It also documents the sensitivity of the consensuses to the strength of tuning of the water reduction actor's strength, from $80 \%$ down to $50 \%$. In all cases, scenario 7 had the strongest support. Indeed, even when the perceived importance of reducing water consumption was dramatically reduced, this scenario retained strong political support. This is an interesting and gratifying result, as the scenarios with the next strongest support (4 \& 5) would not meet the Ministry of Agriculture 2030 goal of $30 \%$ reduction. 
In scenario 7, wheat and fodder are both eliminated, grain production is significantly decreased, and there is an increase in dairy, fruit, meat, and vegetables. Note the implication that a large reduction in water consumption - almost to the stretch goal of $50 \%$ - is more politically palatable than less aggressive scenarios with moderate decreases in production across a large portfolio of crops. This suggests that it may be more socially acceptable to eliminate a few large, water intensive, low-value added crops than to reduce several medium-value added crops.

\section{CONCLUDING REMARKS}

In this article, we have documented two forms of quantitative models of collective decision-making processes - specifically those based on the informal exertion of influence. This is an important set of models, because actual votes cast in many situations are ultimately the result of prior informal negotiation. The Spatial Model of Politics is a powerful tool for the political analyst modeling policy questions which can be represented as a multidimensional continuous spectrum. However, not all policy questions can be represented in this manner. The Probabilistic Condorcet Election is a second, and completely general, form of CDMP model that imposes almost no structure on the problem analyzed.

These, and other, models are encoded in the KAPSARC Toolkit for Behavioral Analysis, a free open-source modeling framework used to build CDMP models. KTAB is being developed by the King Abdullah Petroleum Studies and Research Center to meet the need for widely available, state-of-the-art, supported, transparent, and open-source software that facilitates the modeling and analysis of collective decision-making processes. We summarized insights from two case studies modeled with KTAB, in which important policy questions in the Arab Gulf region were analyzed.

There are a wealth of possibilities of further work on CDMP models and their analysis, and also for the KTAB framework. The data for SMPs come from interviews of experts, but this can be a long, expensive process, and experts are fallible. Worse yet, even experts can be unaware of their own fallibility. Advanced machine learning techniques of text mining could perhaps be used to automate the elicitation of input data from published documents. CDMP models can be parameterized in many ways. For example, KTAB currently has five forms of the victory probability model in (9): binary, linear, square, quartic, and octic. Indeed, CDMP models have potentially many more parameters than this article has detailed. A major question that needs to be resolved is the sensitivity of model results to the values chosen for these parameters - not to mention sensitivity to the actual data values. In addition to these topics, we are currently researching advanced techniques for visualizing CDMP model results, focusing on the inter-iteration bargain proposal process.

Finally, there is a major shortcoming of many joint models of policy and economy: that economic models typically treat policy choices as exogenously specified, while strategic models of policy negotiation typically use simple, fixed models of economics on which all actors must agree. In practice, political interactions and economic policies are entwined, as each may be affected by the details of the other. The PCE is sufficiently flexible that each actor can have an individual utility function that could be a real economic model. We demonstrated this in [38] with a realistically synthesized dataset, and intend to develop such models for real policy questions.

\section{REFERENCES}

[1] M Abdollahian, M Baranick, B Efird, and J Kugler. 2006. Senturion: A Predictive Political Simulation Model. Defense Technology Paper DTP-032. United States Department of Defense.

[2] M Al-Shayaa, M Baig, and G Straquadine. 2012. Agricultural Extension in the Kingdom of Saudi Arabia: Difficult Present and Demanding Future. Fournal of Animal and Plant Sciences 22, 1 (2012), 239-246.

[3] K Arrow. 1950. A Difficulty in the Concept of Social Welfare. Fournal of Political Economy 58, 4 (1950), 328-346.

[4] K Arrow and E Maskin. 1951. Social Choice and Individual Values. Yale University Press, New Haven, Connecticut, USA.

[5] S Bennett and A Stam. 2000. A Universal Test of an Expected Utility Theory of War. International Studies Quarterly 44 (2000), 451-480.

[6] D Black. 1948. On the Rationale of Group Decision-Making. The fournal of Political Economy 56, 1 (1948), 23-34.

[7] A Brown and M Matlock. 2011. A Review of Water Scarcity Indices and Methodologies. White Paper \#106. University of Arkansas: The Sustainability Consortium.

[8] B Buena de Mesquita. 1981. The War Trap. Yale University Press, New Haven, Connecticut, USA.

[9] B Buena de Mesquita. 1985. The War Trap Revisited: A Revised Expected Utility Model. The American Political Science Review 79, 1 (March 1985), 156-177.

[10] B Buena de Mesquita. 1994. European Community Decision Making. Yale University Press, New Haven, Connecticut, USA, Chapter Political Forecasting: an Expected Utility Method, 71-104.

[11] B Buena de Mesquita. 1997. A Decision Making Model: Its Structure and Form. International Interactions 23, 3-4 (1997), 235-266. https://doi.org/10.1080/ 03050629708434909

[12] B Buena de Mesquita. 2002. Predicting Politics. The Ohio State University Press, Columbus, Ohio, USA.

[13] B Buena de Mesquita and D Lalman. 1986. Reason and War. American Political Science Review 80 (1986), 1113-1129.

[14] B Buena de Mesquita and D Lalman. 1992. War and Reason: Domestic and International Imperatives. Yale University Press, New Haven, Connecticut, USA.

[15] J Chung and G de Clerq. 2017. UAE Delays Launch of First Nuclear Power Reactor. Reuters (4 May 2017). http://www.reuters.com/article/ us-kepco-emirates-nuclearpower-exclusive-idUSKBN1801ZD

[16] M Condorcet. 1785. Essay on the Application of Analysis to the Probability of Majority Decisions. (1785).

[17] P Coughlin. 1992. Probabilistic Voting Theory. Cambridge University Press, Cambridge, Massachusetts, USA

[18] B Efird, L Lester, and B Wise. 2016. Analyzing Coalitions in China's Policy Formulation: Reforming the Role of State-owned Enterprises in China's Energy Sector. Journal of East Asian Studies 16, 1 (2016), 117-145. https://doi.org/10. 1017/jea.2015.4

[19] B Efird, P Mollet, I Al Mubarak, S Sgouridis, and I Tsai. 2017. The Political Feasibility of Policy Options for the UAE's Energy Transition. Discussion Paper KS-2017-DP22. King Abdullah Petroleum Studies and Research Center \& Masdar Institute.

[20] S Feder. 2002. Forecasting for Policy Making in the Post Cold War Period. Annual Review of Political Science 5 (2002), 111-125.

[21] S Griffiths. 2017. A Review and Assessment of Energy Policy in the Middle East and North Africa Region. Energy Policy 102 (2017), 249-269.

[22] A Jeffreys. 2011. The Report: Saudi Arabia 2010. Oxford Business Group, Oxford, England.

[23] T Lippman. 2010. Saudi Arabia's Quest for Food Security. Middle East Policy 17, 1 (2010), 123-231. https://doi.org/10.1111/j.14754967.2010.00428.x

[24] C Napoli, B Wise, D Wogan, and L Yaseen. 2016. Policy Options for Reducing Water for Agriculture in Saudi Arabia. Discussion Paper KS-1630-DP024A. King Abdullah Petroleum Studies and Research Center.

[25] T Negishi. 1972. General Equilibrium Theory and International Trade. NorthHolland Publishing Company, Amsterdam, The Netherlands.

[26] T Persson and G Tabellini. 2002. Political Economics: Explaining Economic Policy. MIT Press, Cambridge, Massachusetts, USA.

[27] K Poole and H Rosenthal. 1985. A Spatial Model for Legislative Roll Call Analysis. American Journal of Political Science 35 (1985), 228-278.

[28] K Poole and H Rosenthal. 1991. Patterns of Congressional Voting. American Journal of Political Science 29 (1991), 357-384.

[29] K Poole and H Rosenthal. 1999. D-Nominate after 10 Years: A Comparative Update To Congress: A Political Economic History of Roll Call Voting. Social Science Research Network (1999).

[30] K Poole and H Rosenthal. 2000. Congress: A Political-economic History of Roll Call Voting. Oxford University Press, Oxford, England. 
[31] J Scholz, G Calbert, and G Smith. 2011. Unravelling Bueno de Mesquita's Group Decision Model. fournal of Theoretical Politics 23, 4 (2011), 510-531.

[32] F Stokman, M van Assen, J van der Knoop, and R van Oosten. 2000. Strategic Decision Making. Advances in Group Processes 17 (2000), 131-153.

[33] F Stokman and R van Oosten. 1994. European Community Decision Making. Yale University Press, New Haven, Connecticut, USA, Chapter The Exchange of Voting Positions: An Object-Oriented Model of Policy Networks, 105-128.

[34] A Tversky and D Kahneman. 1974. Judgment Under Uncertainty: Heuristics and Biases. Science 185, 4157 (September 1974), 1124-1131.

[35] A Tversky and D Kahneman. 1979. Prospect Theory: An Analysis of Decision Under Risk. Econometrica 47, 2 (March 1979), 263-290

[36] United Arab Emirates Ministry of Energy. 2017. UAE State of Energy Report, 2017. UAE Energy Strategy 2050. (2017).

[37] B Wise and S Bankes. 2015. Non-spatial Probabilistic Condorcet Election Methodology. ArXiv e-prints 1505.02509 (May 2015). arXiv:cs.GT/1505.02509 https://arxiv.org/abs/1505.02509v1

[38] B Wise, J A Howe, and B Efird. 2017. Toward the Integration of Policymaking Models and Economic Models. Methodology Paper KS-2017-MP03. King Abdullah Petroleum Studies and Research Center.

[39] B Wise, L Lester, and B Efird. 2015. Multidimensional Bargaining Using KTAB. Discussion Paper KS-1524-DP018A. King Abdullah Petroleum Studies and Research Center. 